Check for updates

Cite this: RSC Adv., 2017, 7, 32452

\title{
A two-stage pretreatment using acidic dioxane followed by dilute hydrochloric acid on sugar production from corn stover
}

\author{
Shengxin An, ${ }^{\text {ab }}$ Wenzhi Li, (D) *a Qiyu Liu, ${ }^{a}$ Minghao Li, ${ }^{a}$ Qiaozhi Ma, ${ }^{a}$ Longlong Ma*c \\ and Hou-min Chang ${ }^{\text {d }}$
}

A two-stage pretreatment method was developed to improve sugar recovery in this study. Firstly, the corn stover was pretreated with acidic dioxane to remove lignin, then the residue was subjected to dilute hydrochloric acid to eliminate the negative effects of hemicelluloses on enzymatic hydrolysis as well as increasing xylose yield. The optimal condition was $90^{\circ} \mathrm{C}, 20 \mathrm{~min}$, and $9 / 1(\mathrm{v} / \mathrm{v})$ dioxane-water including $1.0 \mathrm{wt} \% \mathrm{HCl}$ solution in the first stage followed by $120^{\circ} \mathrm{C}$ and $40 \mathrm{~min}$ for $1.0 \mathrm{wt} \%$ dilute hydrochloric acid in the second stage. The total yields of glucose and xylose were $91.5 \%$ and $79.7 \%$, respectively, with

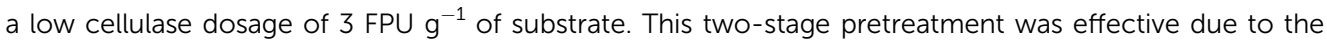
removal of lignin in the first stage and the hydrolysis of hemicelluloses in the second stage, resulting in a very high sugar recovery with a low enzyme loading.

Received 10th May 2017

Accepted 16th June 2017

DOI: $10.1039 / \mathrm{c} 7 \mathrm{ra05280d}$

rsc.li/rsc-advances

biological pretreatment ${ }^{20,21}$ and so on. No matter which method

\section{Introduction}

The shortage of fossil energy and environmental pollution have aroused increasing interest in the utilization of lignocellulosic biomass, ${ }^{1,2}$ a kind of abundant renewable resource, containing plenty of carbohydrates (cellulose and hemicelluloses). The carbohydrate in biomass could be hydrolyzed into monosaccharides, which can be further converted into diverse biofuels and chemicals. $^{3-5}$ However, the utilization of lignocellulose is hindered by its natural tight three-dimensional structure mainly composed of lignin, hemicellulose and cellulose, ${ }^{6,7}$ and as a consequence pretreatment is compulsory before hydrolysis. The objective of pretreatment is to destroy its complex structure and to produce a cellulose-rich substrate which is sensitive to enzymatic hydrolysis (i.e., to supply fast conversion of cellulose into glucose at low enzyme dosage).

For this purpose, various pretreatment methods have been investigated during the past decades. Commonly reported methods include physical, chemical, biological and physicochemical treatments, such as milling, ${ }^{8,9}$ dilute acid, ${ }^{10,11}$ alkaline, ${ }^{12,13}$ hot water, ${ }^{14,15}$ organic solvent, ${ }^{16,17}$ ionic liquid, ${ }^{18,19}$

${ }^{a}$ Laboratory of Basic Research in Biomass Conversion and Utilization, Department of Thermal Science and Energy Engineering, University of Science and Technology of China, Hefei 230026, PR China. E-mail: liwenzhi@ustc.edu.cn; Tel: +86-0551-63600786

${ }^{b}$ Institute of Chemical Engineering, Anhui University of Science and Technology, Huainan 232001, PR China

${ }^{c}$ Guangzhou Institute of Energy Conversion, Chinese Academy of Sciences, Guangzhou 510650, PR China.E-mail: mall@ms.giec.ac.cn

${ }^{d}$ Department of Forest Biomaterials, North Carolina State University, Raleigh, NC 27695-8005, USA was used, the fundamental objective was to reduce hemicelluloses and lignin contents, increase porosity and surface area, and decrease crystallinity and fibre size. ${ }^{22}$

Although the pretreatment methods mentioned above have demonstrated positive effects on lignocelluloses hydrolysis, it is still difficult to maximize the utilization of lignocelluloses via one-stage pretreatment due to its natural recalcitrant structure composed of cellulose, hemicelluloses and lignin.. ${ }^{23,24}$ Therefore, a two-stage pretreatment method has been developed. The main purpose of two-stage pretreatment method was to destroy the compact structure of lignocelluloses by the removal of lignin and hemicelluloses ${ }^{25-27}$ which allow cellulose to be more accessible to cellulase, resulting in a high glucose recovery with a low enzyme dosage. In this way, hemicelluloses and cellulose could be recovered under optimum conditions respectively, reaching a target of integrated utilization of lignocelluloses.

During two-step process, dilute acid pretreatment was frequently used to hydrolyze hemicelluloses and recover pentose. ${ }^{8,28}$ The removal of hemicelluloses could increase the porosity and facilitate the accessibility of enzyme to cellulose. However, dilute acid pretreatment only shows negligible impact on lignin removal. Lignin existing in biomass has an unfavorable effect on enzymatic hydrolysis for glucose because of its adsorption for cellulases and physical barrier around cellulose..$^{29-31}$ In order to further destroy lignocellulosic structure and obtain high glucose yield, it is necessary to implement a delignification process.

Organic solvent pretreatments were extensively applied in view of the significant efficacy on lignin removal. However, most of organic solvent pretreatment process such as ethanol pretreatments (with or without catalyst) required relatively high 
temperature, long reaction time and high enzyme dosage, ${ }^{17,27,32}$ which went against industrial applications. Compared with those solvents, 1,4-dioxane could be a splendid organic solvent being used in pretreatment on account of low boiling point, excellent solubility of lignin, easy recovery and mild reaction condition. As high as $74.14 \%$ lignin could be obtained from bioethanol production residue by dioxane extraction, ${ }^{33}$ which implies 1,4-dioxane/water solution plays an effective role in lignin extraction and could be used in the pretreatment process. However, the delignification effect was poor in pure dioxane solution. This condition could be improved if acid catalysts (organic or mineral acids) were added into 1,4-dioxane solution (named acidic dioxane solution), $\mathrm{H}^{+}$could cleave intermolecular bonds existed in lignin, hemicelluloses and lignin-carbohydrate complex (LCC), causing plenty of lignin and small amount of hemicelluloses degraded and dissolved into acidic dioxane solution. Therefore, acidic dioxane pretreatment can deconstruct the compact structure of biomass, and facilitate enzymatic hydrolysis for glucose recovery.

With the aim to recover glucose and xylose as much as possible with a lower cellulase loading and less energy input, a novel twostage pretreatment process using acidic dioxane followed by dilute acid pretreatment was developed in this research. During the first stage, a large proportion of lignin and part of hemicelluloses were removed under optimal conditions by acidic dioxane pretreatment (dioxane-water solution mixed with certain amount of $\mathrm{HCl}$ ). The lignin and hemicelluloses solubilized in dioxane solution could be recovered directly or further converted into other high-value chemicals or liquid fuels in this system, which enabled acidic dioxane solution recyclable. Despite of partial degradation of hemicellulose in the first stage, the remained hemicelluloses in the residue still had an unfavorable effect on glucose enzymatic hydrolysis, leading to the decrease of glucose yield. ${ }^{34,35}$ A subsequent dilute hydrochloric acid pretreatment was designed to eliminate this negative effect. After that process, the compact structure of biomass was broken, exposing the active sites of cellulose, increasing accessible surface area and making the enzymatic hydrolysis more effective. At the same time, the xylose could be recovered respectively through two stage, reaching to the target of sufficient utilization of lignocelluloses. To achieve a high sugar yield, reaction conditions were investigated and optimized in this study. The structural change before and after pretreatment were characterized by a series of analytical methods, including scanning electron microscopy (SEM) images and Brunner-Emmet-Teller (BET) in order to evaluate the impacts of two-stage pretreatment on corn stover.

\section{Material and methods}

\subsection{Materials}

The corn stover was obtained from the northern Anhui province of China. The biomass was washed, dried, milled and stored using the methods in our previous work. ${ }^{8}$ 1,4-dioxane and $\mathrm{HCl}$ were provided by Sinopharm Group Chemical Reagent Co., Ltd (Shanghai, China). Enzymes were donated by Novozymes (China) Investment Co., Ltd. All chemical reagents had no further purification before use.

\subsection{Two stage pretreatment of corn stover}

In the first stage, $4 \mathrm{~g}$ dried corn stover and $40 \mathrm{~mL}$ different acid concentrations $(0.2,0.4,0.6,1.0,1.2$ and $1.5 \mathrm{wt} \%)$ in dioxane solution were mixed in $70 \mathrm{~mL}$ batch reactor with agitation. Different temperature $\left(70,80\right.$ and $\left.90{ }^{\circ} \mathrm{C}\right)$, reaction time $(10,20$, 30,40 and $50 \mathrm{~min}$ ), dioxane-water ratios $(1: 1,4: 1,9: 1,12: 1$, $\mathrm{v} / \mathrm{v}$ ) have been investigated. After pretreatment, the reactors was removed from the heating jacket and directly cooled to room temperature with circulating water. Then the obtained hydrolysate was separated from the residues by filtration. The hydrolysate was divided into halves, one half was used to analyze the lignin recovery and the other half was analyzed to determine its glucose, xylose and lignin contents. The optimal condition was chosen according to the consumption of energy and acid as well as the recovery of glucose, xylose and lignin. All the reactions were conducted in duplicated. The solid residue was used for the second stage pretreatment.

In the second dilute acid stage, the wet residue from the first stage was further pretreated under the optimal conditions (1 wt\% $\mathrm{HCl}, 120{ }^{\circ} \mathrm{C}, 40 \mathrm{~min}$ ) which were investigated in our previous work. ${ }^{36}$ After this process, the residual solid was collected by filtration, washed with deionized water until it was free of acid and then stored for enzyme hydrolysis stock. The hydrolysate was collected to determine the glucose and xylose content with the same method in the first stage.

\subsection{Enzymatic hydrolysis}

Enzymatic hydrolysis was performed by using a cellulase concentrate (Cellulast $1.5 \mathrm{~L}$ ) supplemented with $\beta$-glucosidase (Novozym 188), both from Novozymes (China) Investment Co., Ltd. The enzyme activities was 67.8 filter paper units (FPU) per $\mathrm{mL}$ (expressed as micromoles of glucose produced per minute, with filter paper as a substrate) and 210.5 cellobiose units (CBU) per $\mathrm{mL}$ (expressed as micromoles of cellobiose that is converted to glucose per minute, with cellobiose as a substrate) for Celluclast 1.5 L and Novozyme 188, respectively. ${ }^{37}$ Enzymes were directly used without further purification.

The enzymatic hydrolysis of untreated and wet pretreated samples ( $0.2 \mathrm{~g}$ dry substrate) were conducted in a centrifuge tube containing $50 \mathrm{mM}$ sodium acetate buffer $(\mathrm{pH} 4.8)$. The mass concentration was set at $5 \%(\mathrm{w} / \mathrm{v})$. Sodium azide $(0.3 \%, \mathrm{w} /$ v) was also added for inhibiting the microbial infection. Cellulase (3, 5 and 10 FPU per gram substrate) and $\beta$-glucosidase (20 CBU per gram substrate) were added into the tube as well. The enzyme hydrolysis experiments were performed in a shaking incubator at $50{ }^{\circ} \mathrm{C}, 120 \mathrm{rpm}$. After $72 \mathrm{~h}$, the hydrolysate was separated from the mixture by centrifugation at $8000 \mathrm{rpm}$ for $1 \mathrm{~min}$. Glucose yield released in the hydrolysate were determined by high performance liquid chromatography (HPLC). Each reaction was carried out in duplicates.

\subsection{Analysis methods}

2.4.1 Composition analysis of raw and pretreated biomass. The chemical compositions (glucan, xylan, arabinan, acidinsoluble lignin, acid-soluble lignin, extractive, ash and 
others) of the untreated and pretreated corn stover samples were measured according to National Renewable Energy Laboratory (NREL) analytical procedures. ${ }^{38-40}$

2.4.2 Sugar determination. The glucose and xylose concentration in the hydrolysate were determined by a Waters 2414 HPLC system equipped with an Aminex HPX-87H column (Bio-Rad $300 \mathrm{~mm} \times 7.8 \mathrm{~mm}, 5 \mu \mathrm{m}$ ) and an Refractive Index Detector (waters 2414, USA). $5 \mathrm{mM} \mathrm{H}_{2} \mathrm{SO}_{4}$ acted as mobile phase under a flow rate of $0.6 \mathrm{~mL} \mathrm{~min}^{-1}$. The temperature of column and oven were $63{ }^{\circ} \mathrm{C}$ and $50{ }^{\circ} \mathrm{C}$, respectively. The final sugar yield was the sum total of sugars produced during pretreated stage and enzymatic hydrolysis. The yields of glucose and xylose were calculated as follows:

Glucose yield $=[$ (grams of glucose produced in the hydrolyzate $)$ $\times 0.9] /($ grams of glucan in raw biomass $) \times 100 \%$

Xylose yield $=[$ (grams of xylose produced in the hydrolyzate $)$ $\times 0.88] /($ grams of xylan in raw biomass $) \times 100 \%$

2.4.3 Lignin determination. Lignin recovery in this study was calculated only based on the lignin obtained in the first pretreatment stage. After reaction, the filtrate obtained from acidic dioxane pretreatment was condensed into about $5 \mathrm{~mL}$ by rotary evaporation, then the concentrated solution was diluted into 20 times volumes of water to precipitate lignin. Meanwhile most of dioxane could be recovered in this process. Lignin was obtained by centrifugation, washed twice with water to remove additional dioxane and sugars, dissolved into $5 \mathrm{~mL}$ acidic dioxane solution, and then dropped into 20 times volume of diethyl-ether to precipitate lignin again. ${ }^{41}$ The lignin was extracted by diethyl ether several times at room temperature and then kept in a vacuum oven at $80{ }^{\circ} \mathrm{C}$ overnight and weighed to determine the lignin recovery.

2.4.4 Scanning electron microscopy (SEM). The morphology of untreated, acidic dixoane pretreated, dilute hydrochloride acid pretreated and two-stage pretreated corn stover samples was characterized by SEM at a magnification of 2000 times and accelerating voltage of $10 \mathrm{kV}$. Before analysis, all samples were freeze-dried to reserve their post-pretreatment structures and raw material was used directly. All samples were first sputter-coated with a thin layer of gold before imaging.

2.4.5 Porosity. Porosity, including specific surface area and total pore volume, had a significant effect on enzymatic hydrolysis. The porosity of the freeze-dried acidic dixoane pretreated, dilute hydrochloride acid pretreated, two-stage pretreated corn stover and untreated raw material were measured. The specific surface (SSA) of samples were determined on Tristar $113020 \mathrm{M}$ instrument from Micromeritics by the Brunauer-Emmett-Teller (BET) method. The analysis was conducted using $\mathrm{N}_{2}$ as adsorption/desorption isotherms. The total volume of pores was calculated by single point adsorption total pore volume of pores with $P / P_{0}$ at 0.973 .

2.4.6 Degree of polymerization. Cellulose from corn stover was the direct substrate of enzymatic hydrolysis reaction in this study. The cellulose viscosity average degree of polymerization (DPv) of lignocellulosic biomass could reflect the difficulty level of hydrolysis and was determined according to ATSM standard D1975. ${ }^{42}$ However, whether the corn stover was pretreated or untreated, they could not completely be dissolved in $0.5 \mathrm{M}$ copper diethyleneamine solution due to the existence of lignin. On the other hand, further delignification of corn stover could lead to undesired effect on cellulose DPv. The method used to determine the cellulose DPv was reported by Kumar et al. (2009), ${ }^{43}$ which assumed that both unsolubilized and solubilized fractions had similar compositions. A small amount of dried and pulverized powder untreated and pretreated corn stover was used to minimize the lignin effect on viscosity. After a mixing time of about $30 \mathrm{~min}$ at $70{ }^{\circ} \mathrm{C}$ in a thermostated shaker water bath unit, the unsolubilized fraction was filtered out from the solution and weighed. The solubilized fraction was then used to determine the intrinsic viscosity $\left(\mathrm{dl} \mathrm{g}^{-1}\right)$ according to ASTM standard D 1795. ${ }^{42}$ After the intrinsic viscosity was determined, the $\mathrm{DPv}$ was calculated according to a relation:

$$
\mathrm{DP}=[(1.65 \eta-116 H) / G]^{1.11}
$$

in which, $\eta$ is the intrinsic viscosity $\left(\mathrm{cm}^{3} \mathrm{~g}^{-1}\right)$ and $H$ and $G$ are the mass fraction of hemicellulose (mainly xylan) and glucan, respectively.

\section{Results and discussion}

\subsection{Effect of pretreatment methods on sugar recovery}

The chemical compositions of raw material were as follows: $32.6 \%$ glucan, $22.5 \%$ xylan, $2.9 \%$ arabinan, $1.3 \%$ galactan, $17.6 \%$ acid-insoluble lignin (Klasen lignin), 3.1\% acid-soluble lignin, $9.8 \%$ extractive, $4.1 \%$ ash and $6.1 \%$ other components.

In this study, three pretreatment approaches were performed to find a method leading to the higher glucose yield. These methods included: dilute hydrochloric acid pretreatment (HP), acidic dioxane pretreatment (ADP), and acidic dioxane followed by dilute hydrochloric acid pretreatment (ADPH). HP was proceeded at $120{ }^{\circ} \mathrm{C}$ for $40 \mathrm{~min}$. ADP was proceeded at $90{ }^{\circ} \mathrm{C}$ for $20 \mathrm{~min}$ in $9: 1(\mathrm{~V} / \mathrm{V})$ dioxane-to-water solution containing 1.0 wt $\% \mathrm{HCl}$. ADPH was proceeded at $\left.90{ }^{\circ} \mathrm{C}, 20 \mathrm{~min}, 9 / 1 \mathrm{v} / \mathrm{v}\right)$ dioxane-water including $1.0 \mathrm{wt} \% \mathrm{HCl}$ solution in the first stage followed by $120^{\circ} \mathrm{C}$ and $40 \mathrm{~min}$ for $1.0 \mathrm{wt} \%$ dilute hydrochloric acid in the second stage. The results of the effect of different processes on enzymatic hydrolysis were shown in Fig. 1.

From Fig. 1a, the sum of glucose yield obtained from the first stage and the second stage during ADPH process was less than $8.0 \%$, which suggested that most of cellulose remained in the pretreated materials because cellulose is hard to be depolymerized due to its semi-crystalline structures. Compared with $\mathrm{HP}, \mathrm{ADP}$ and ADPH, the glucose yield of untreated material after enzymatic hydrolysis was very low $(17.2 \%$ with a cellulase dosage of $3 \mathrm{FPU} \mathrm{g}^{-1}$ substrate), indicating that natural compact structure of corn stover was detrimental to enzymatic hydrolysis. After HP and ADP process, glucose yields were increased by $31.5 \%$ and $37.6 \%$ respectively at $3 \mathrm{FPU} \mathrm{g}^{-1}$ substrate, which 

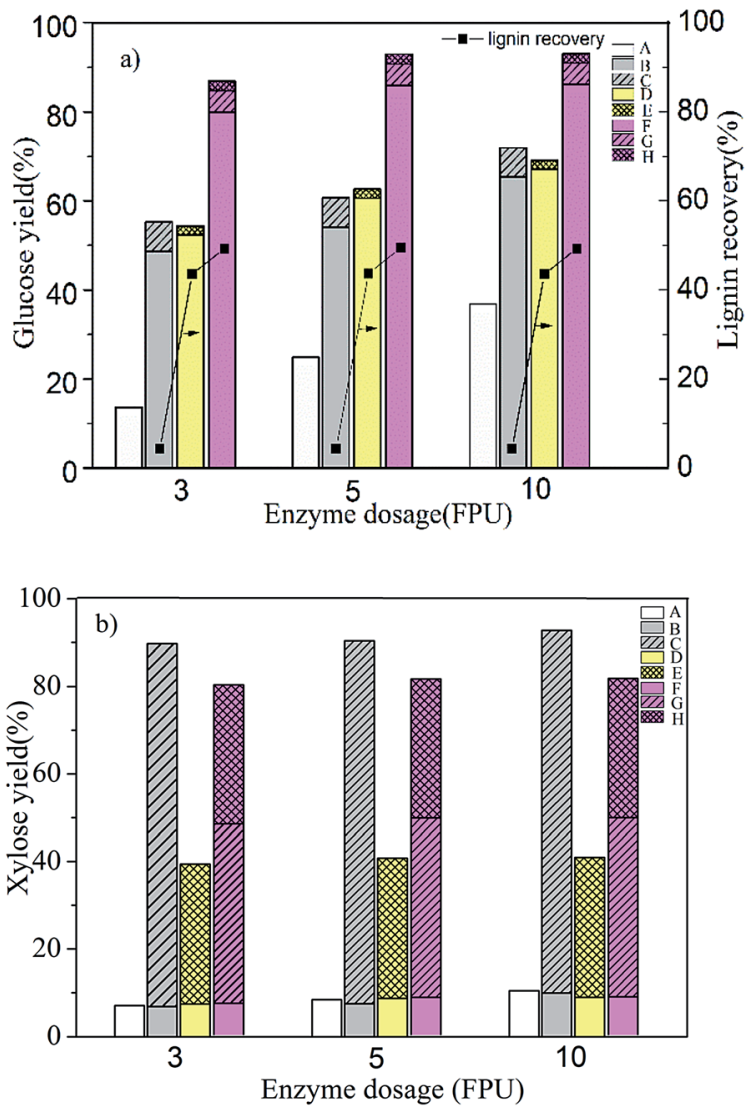

Fig. 1 Effect of different pretreatment methods on sugar yield ((A) sugar yields of untreated samples after enzymatic hydrolysis; (B) sugar yields obtained in enzymatic hydrolysate after $\mathrm{HCl}$ pretreatment; (C) sugar yields obtained in $\mathrm{HCl}$ pretreatment stage; (D) sugar yields obtained in enzymatic hydrolysate after acidic dioxane pretreatment; $(E)$ sugar yields obtained in acidic dioxane pretreatment stage; (F) sugar yields obtained in enzymatic hydrolysate after two-stage pretreatment; (G) sugar yields obtained in the first stage by $\mathrm{HCl}$ pretreatment; (H) sugar yields obtained in the second stage by acidic dioxane pretreatment).

was ascribed to the fact that HP and ADP could increase the dissolution of hemicelluloses (up to $83.9 \%$ in HP process and $32.1 \%$ in ADP process, Fig. 1b). In addition, ADP process had a great advantage on lignin solubilization (up to $49.3 \%$, Fig. 1a). Both hemicelluloses hydrolysis and delignification could contribute a lot to enzymatic hydrolysis. ${ }^{44}$ But the weak effect on delignification in HP process (4.2\% lignin removed, Fig. 1a) and the finite effect on hemicelluloses hydrolysis in ADP process seemed to have a limited impact for increasing the glucose yield during enzymatic hydrolysis. Then ADPH was investigated. After ADPH, the yield of xylose and lignin was $72.5 \%$ and $49.5 \%$ respectively (Fig. 1a and b). That removal of a large amount of lignin and hemicelluloses in corn stover destroyed its tight structure (Fig. 3d), reduced the absorption amount of lignin to cellulose enzyme, improved the accessibility of carbohydrates to enzyme, resulting in a high yield of glucose in enzymatic hydrolysis under a low enzyme loading (91.5\% glucose yield with a cellulase dosage of $3 \mathrm{FPU} \mathrm{g}^{-1}$ substrate). Besides an acceptable xylose yield of $79.7 \%$ was obtained after ADPH
(31.5\% obtained in the first stage, $41.0 \%$ obtained in second stage and $7.2 \%$ obtained in enzymatic stage with a cellulase dosage of 3 FPU $\mathrm{g}^{-1}$ substrate, Fig. 1b), which demonstrated that hemicelluloses presented in biomass were easier to be hydrolyzed. The results indicated that ADPH was a more effective method than single-step pretreatment using either HP or ADP to improve sugars especially glucose recovery.

\subsection{Effect of the order of acidic dioxane process used in the two-stage pretreatment method on sugar recovery}

The effect of the order of acidic dioxane process used in the twostage pretreatment method was also studied. HADP was also a two-stage pretreatment method using dilute hydrochloric acid followed by acidic dioxane pretreatment, which was conducted with $1.0 \mathrm{wt} \% \mathrm{HCl}$ at $120{ }^{\circ} \mathrm{C}$ for $40 \mathrm{~min}$ in the first stage followed by $80{ }^{\circ} \mathrm{C}, 30 \mathrm{~min}, 9 / 1(\mathrm{v} / \mathrm{v})$ dioxane-water including $1.0 \mathrm{wt} \% \mathrm{HCl}$ solution in the second stage. The only difference between ADPH and HADP was the order of acidic dioxane process used in the two-stage pretreatment.

Fig. 2a clearly indicated that ADHP had a larger impact on glucose recovery than HADP with a yield of $80.3 \%$ at 3 FPU enzyme dosage $\left(80{ }^{\circ} \mathrm{C}, 30 \mathrm{~min}, 1 \mathrm{wt} \%\right.$ acidic dioxane, $10: 1$ liquid-solid ratio). The results may be explained as follows: after ADPH, a large amount of lignin (44.9\%) and hemicelluloses (77.6\% xylose yield) were removed from the biomass, which enhanced enzymatic accessibility and increase the glucose recovery. During HADP process, due to most of hemicelluloses (83.9\% xylose yield, Fig. 2b) had been hydrolyzed in the first stage, $\mathrm{H}^{+}$, as a catalyst, catalyzed lignin repolymerization on the surface of cellulose,${ }^{45}$ enhancing the physical barrier for enzymatic hydrolysis and resulting in a lower glucose yield than ADPH. Besides, it was worth noting that xylose yield obtained from $\mathrm{ADPH}$ was lower than that from HADP $(77.6 \%$ in $\mathrm{ADPH}$ and $83.9 \%$ in HADP, excluding the yield of enzymatic process, Fig. 2b). This could be ascribed to the fact that partial of xylose converted into furfural and organic acid in the first stage at set reaction condition. These results were in agreement with previous study that the organosolv pretreatment with acid catalysts might cause the degradation of pentose generating new compounds chemical compounds. ${ }^{46,47}$ To achieve maximum utilization of lignocellulosic biomass, the yield of both xylose and glucose must be simultaneously considered in this study. Compared with HADP, the yield of glucose and xylose gained from $\mathrm{ADPH}$ 80.1\% and 84.9\% respectively $59.1 \%$ and 90.1\% in HADP), which demonstrated ADPH was a better pretreatment method.

\subsection{Effect of dioxane-to-water ratio on sugar recovery}

The effect of different dioxane-to-water ratio $(1: 1,4: 1,9: 1$, $12: 1, \mathrm{v} / \mathrm{v})$ in $1 \mathrm{wt} \% \mathrm{HCl}$ dioxane solution $(\mathrm{v} / \mathrm{v})$ in $1 \mathrm{wt} \% \mathrm{HCl}$ dioxane solution $n$ enzymatic hydrolysis was investigated and the results were illustrated in Table 1.

As shown in Table 1, it was clear that glucose yield in enzymatic hydrolysis process increased with an increase of dioxaneto-water ratio. However, there was almost no further improvement on glucose yield while dioxane-to-water ratio increased 

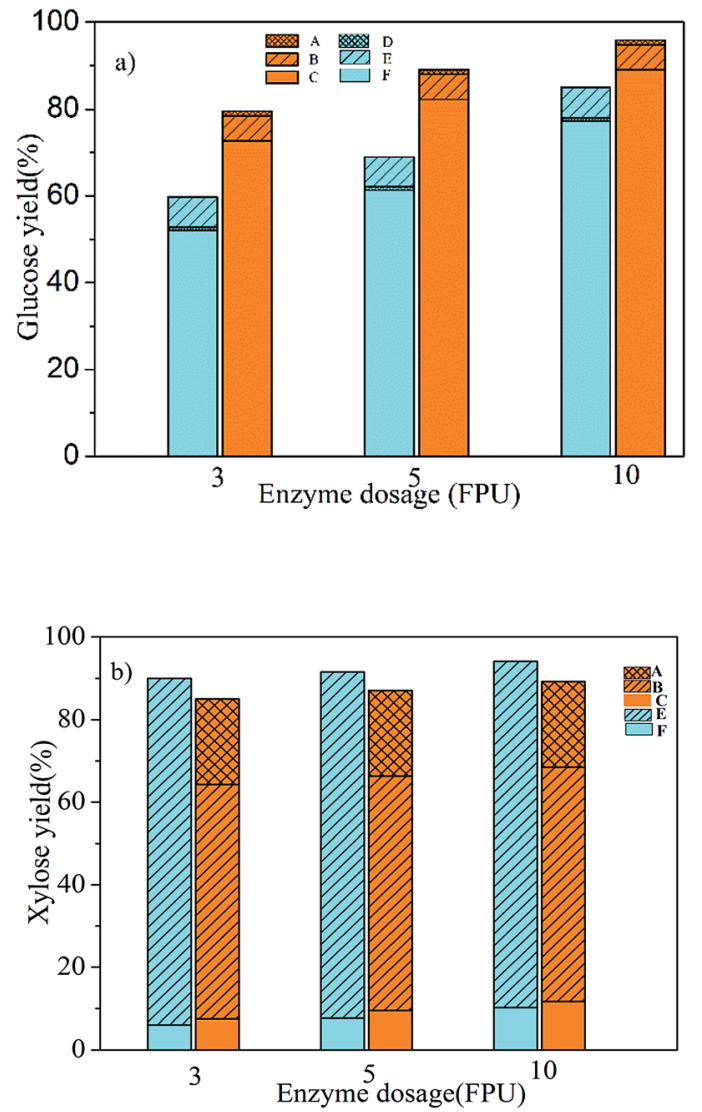

Fig. 2 Effect of different two-stage pretreatment processes on sugar yield ((A) sugar yields obtained in acidic dioxane hydrolysate after twostage pretreatment with $\mathrm{HCl}$ used in the second stage; (B) sugar yields obtained in $\mathrm{HCl}$ hydrolysate after two-stage pretreatment with $\mathrm{HCl}$ used in the second stage; (C) sugar yields obtained in enzymatic hydrolysate after two-stage pretreatment with $\mathrm{HCl}$ used in the second stage; (D) sugar yields obtained in acidic dioxane hydrolysate after two-stage pretreatment with $\mathrm{HCl}$ used in the first stage; (E) sugar yields obtained in $\mathrm{HCl}$ hydrolysate after two-stage pretreatment with $\mathrm{HCl}$ used in the first stage; (F) sugar yields obtained in acidic dioxane hydrolysate after two-stage pretreatment with $\mathrm{HCl}$ used in the first stage).

from $9: 1$ to $12: 1$ in the preset research. The reason was that the dioxane-water ratio used in organosolv pretreatment process was an influential parameter for the delignification of corn stover. At the ratio of $1: 1$, only $18.9 \%$ lignin was achieved because high proportion of water in acidic dioxane solution was adverse to the solubility of lignin. With the increase of dioxane content, a large amount of lignin dissolved into dioxane-water mixture, and the removal of lignin was beneficial for the exposure of cellulose micro-fibris. ${ }^{48}$ Meanwhile, when the ratio ranging from $1: 1$ to $12: 1$, the yield of xylose increased from $5.9 \%$ to $31.5 \%$, then reduced to $11.1 \%$. A supposed reason was that hemicelluloses were hard to be hydrolyzed at such mild conditions as $90{ }^{\circ} \mathrm{C}, 20 \mathrm{~min}, 1: 1$ dioxane-to-water ratio with 1 $\mathrm{wt} \% \mathrm{HCl}$. When dioxane-to-water ratio increased, much more lignin fell off from lignocellulose, resulting in more LCC bands broken, so hemicelluloses could be easy hydrolyzed into xylose. However, the degradation of xylose became serious when further increased dioxane-to-water ratio from $9: 1$ to $12: 1$. Together with the xylose yield obtained from the second stage, a large amount of hemicelluloses were removed and recovered from lignocelluloses during two-stage pretreatment process. The removal of lignin and hemicelluloses could improve the cellulose accessibility for enzymatic hydrolysis and increase the glucose yield obviously. $91.5 \%$ glucose was obtained at $90{ }^{\circ} \mathrm{C}$, $20 \mathrm{~min}, 9: 1$ dioxane-to-water ratio with $1 \mathrm{wt} \% \mathrm{HCl}$. With a view of xylose yield and consumption of chemical reagent, $9: 1(\mathrm{v} / \mathrm{v})$ was chosen as the appropriate dioxane-to-water ratio in $\mathrm{ADPH}$ process.

\subsection{Effect of acidic dioxane solution acidity on sugar recovery}

The effect of acidic dioxane solution acidity $(0.2,0.4,0.6,0.8$, $1.0,1.2,1.5$ wt\% hydrochloric acid) on glucose yield was investigated. Results are shown in Table 2.

As depicted in Table 2, after the two-stage pretreatment, the glucose yield obviously increased from $61.3 \%$ to $85.3 \%$, when the acid concentration was increased from $0.2 \mathrm{wt} \%$ to $1.0 \mathrm{wt} \%$, whereas further increase of acid concentration from 1.0 to 1.5 wt $\%$ only a little increase from $85.3 \%$ to $86.4 \%$ was observed. The results could be explained as follows: with the increase of acid concentration, more $\mathrm{H}^{+}$would get involved in the cleavage of bonds between lignin-carbohydrates or lignin-lignin, leading to much more dissolution of lignin as well as hydrolysis of hemicellulose. Table 2 also shows that the recovery of lignin increased from $18.6 \%$ to $52.1 \%$ when the acid concentration inclined from $0.2 \mathrm{wt} \%$ to $1.5 \mathrm{wt} \%$. However, further increasing acid concentration from $0.8 \%$ to $1.5 \%$, the xylose yield obtained

Table 1 The effect of dioxane-to-water ratio in the first stage on sugar recovery ${ }^{a}$

\begin{tabular}{|c|c|c|c|c|c|c|c|c|c|}
\hline \multirow[b]{2}{*}{ Dioxane $: \mathrm{H}_{2} \mathrm{O}(\%, \mathrm{v} / \mathrm{v})$} & \multirow[b]{2}{*}{ Lignin removal (\%) } & \multicolumn{4}{|c|}{ Glucose yield (\%) } & \multicolumn{4}{|c|}{ Xylose yield (\%) } \\
\hline & & A & $\mathrm{B}$ & $\mathrm{C}$ & Total & A & $\mathrm{B}$ & $\mathrm{C}$ & Total \\
\hline $4: 1$ & 45.9 & 1.9 & 5.4 & 76.4 & 83.7 & 27.5 & 33.3 & 8.3 & 69.1 \\
\hline $9: 1$ & 49.8 & 1.5 & 5.3 & 85.3 & 91.5 & 31.5 & 41.0 & 7.2 & 79.7 \\
\hline $12: 1$ & 52.3 & 1.4 & 5.2 & 85.2 & 91.8 & 11.1 & 45.0 & 5.9 & 64.0 \\
\hline
\end{tabular}

${ }^{a}$ A: glucose yield obtained in the first stage $\left(90^{\circ} \mathrm{C}, 20 \mathrm{~min}, 1 \mathrm{wt} \%\right.$ acidic dioxane, $10: 1$ liquid-solid ratio); B: glucose yield obtained in the second stage $\left(120^{\circ} \mathrm{C}, 40 \mathrm{~min} 1 \mathrm{wt} \% \mathrm{HCl}\right)$; C: glucose yield obtained in enzymatic hydrolysis process (3 FPU enzyme dosage). 
Table 2 The effect of acidic dioxane solution acidity ${ }^{b}$ on sugar recovery ${ }^{a}$

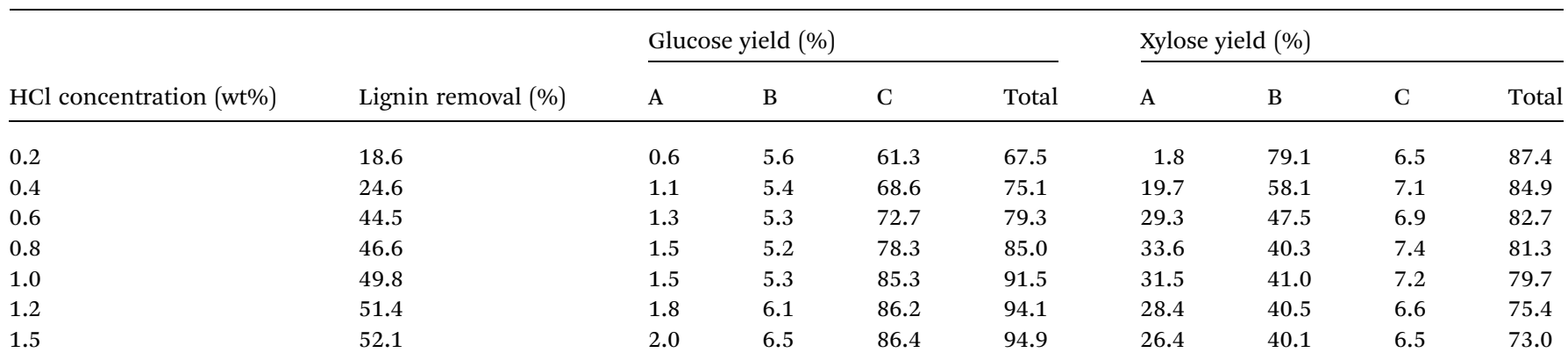

${ }^{a}$ A: glucose yield obtained in the first stage $\left(90^{\circ} \mathrm{C}, 20 \mathrm{~min}, 9: 1\right.$ dioxane-to-water ratio, $10: 1$ liquid-solid ratio); B: glucose yield obtained in the second stage $\left(120^{\circ} \mathrm{C}, 40 \mathrm{~min} 1 \mathrm{wt} \% \mathrm{HCl}\right) ; \mathrm{C}$ : glucose yield obtained in enzymatic hydrolysis process (3 $\mathrm{FPU}$ enzyme dosage). ${ }^{b} \mathrm{HCl}$ concentration in acidic dioxane solution represented acidic dioxane solution acidity in this research.

Table 3 The effect of reaction time and temperature in the first stage on sugar recovery ${ }^{a}$

\begin{tabular}{|c|c|c|c|c|c|c|c|c|c|}
\hline \multirow[b]{2}{*}{ Time and temperature } & \multirow[b]{2}{*}{ Lignin removal (\%) } & \multicolumn{4}{|c|}{ Glucose yield (\%) } & \multicolumn{4}{|c|}{ Xylose yield (\%) } \\
\hline & & A & B & $\mathrm{C}$ & Total & A & $\mathrm{B}$ & $\mathrm{C}$ & Total \\
\hline $70^{\circ} \mathrm{C} 10 \mathrm{~min}$ & 20.3 & 0.5 & 5.2 & 64.1 & 69.8 & 4.1 & 74.6 & 7.4 & 86.1 \\
\hline $70^{\circ} \mathrm{C} 20 \mathrm{~min}$ & 22.8 & 0.6 & 5.6 & 69.8 & 76.0 & 4.6 & 72.2 & 7.5 & 84.3 \\
\hline $70{ }^{\circ} \mathrm{C} 30 \mathrm{~min}$ & 25.5 & 0.6 & 5.5 & 70.7 & 76.8 & 5.7 & 73.7 & 7.7 & 86.1 \\
\hline $70{ }^{\circ} \mathrm{C} 40 \mathrm{~min}$ & 27.0 & 0.7 & 5.8 & 71.9 & 78.4 & 8.9 & 69.0 & 7.7 & 85.6 \\
\hline $70{ }^{\circ} \mathrm{C} 50 \mathrm{~min}$ & 34.6 & 0.8 & 5.8 & 73.6 & 80.2 & 11.2 & 63.0 & 7.8 & 82.0 \\
\hline $80^{\circ} \mathrm{C} 10 \mathrm{~min}$ & 35.6 & 0.9 & 5.5 & 69.5 & 75.9 & 10.6 & 55.6 & 7.0 & 73.2 \\
\hline $80^{\circ} \mathrm{C} 20 \mathrm{~min}$ & 43.7 & 0.9 & 5.6 & 70.3 & 76.8 & 19.2 & 55.5 & 7.2 & 81.9 \\
\hline $80^{\circ} \mathrm{C} 30 \mathrm{~min}$ & 44.9 & 1.0 & 5.7 & 73.4 & 80.1 & 26.2 & 46.8 & 7.4 & 80.4 \\
\hline $80^{\circ} \mathrm{C} 40 \mathrm{~min}$ & 46.8 & 1.1 & 5.8 & 77.5 & 84.4 & 24.1 & 50.3 & 7.4 & 81.8 \\
\hline $80^{\circ} \mathrm{C} 50 \mathrm{~min}$ & 48.1 & 1.3 & 5.9 & 81.2 & 88.4 & 30.7 & 43.1 & 7.4 & 81.2 \\
\hline $90{ }^{\circ} \mathrm{C} 10 \mathrm{~min}$ & 47.6 & 1.5 & 5.2 & 80.3 & 87.0 & 32.3 & 41.3 & 7.1 & 80.7 \\
\hline $90^{\circ} \mathrm{C} 20 \mathrm{~min}$ & 49.8 & 1.5 & 5.3 & 85.3 & 91.5 & 31.5 & 41.0 & 7.2 & 79.7 \\
\hline $90^{\circ} \mathrm{C} 30 \mathrm{~min}$ & 51.0 & 1.5 & 5.4 & 85.9 & 92.8 & 29.1 & 42.5 & 7.4 & 79.0 \\
\hline $90{ }^{\circ} \mathrm{C} 40 \mathrm{~min}$ & 52.1 & 1.7 & 5.5 & 86.1 & 93.3 & 27.3 & 40.0 & 7.3 & 73.6 \\
\hline $90^{\circ} \mathrm{C} 50 \mathrm{~min}$ & 52.7 & 1.8 & 6.0 & 86.3 & 94.1 & 28.1 & 35.8 & 6.6 & 70.5 \\
\hline
\end{tabular}

${ }^{a}$ A: glucose yield obtained in the first stage $(1 \mathrm{wt} \% \mathrm{HCl}$ in dioxane/water solution, $9: 1$ dioxane-to-water ratio, $10: 1$ liquid-solid ratio); B: glucose yield obtained in the second stage $\left(120^{\circ} \mathrm{C} 40 \mathrm{~min} 1 \mathrm{wt} \% \mathrm{HCl}\right)$; C: glucose yield obtained in enzymatic hydrolysis (3 FPU enzyme dosage).

in the first stage obviously decreased from $33.6 \%$ to $22.4 \%$ although the glucose yield and the lignin recovery were still improved, which suggested partial xylose in dioxane-water mixture was converted into other by-products. Together with the xylose yield obtained in the second stage, a large proportion of hemicelluloses were hydrolyzed and recovery from lignocellulose. The removal of lignin and hemicelluloses made the cellulose more accessible to enzymes, achieving a higher efficiency of enzyme hydrolysis and glucose recovery. $79.7 \%$ xylose and $49.5 \%$ lignin were gained at $90{ }^{\circ} \mathrm{C}, 20 \mathrm{~min}, 9 / 1(\mathrm{v} / \mathrm{v})$ dioxane-water including $1.0 \mathrm{wt} \% \mathrm{HCl}$ solution in the first stage by $120^{\circ} \mathrm{C}$ and $40 \mathrm{~min}$ for $1.0 \mathrm{wt} \% \mathrm{HCl}$ in the second stage. To ensure both sugars recovery and equipment corrosion, a relatively low acid concentration of $\mathrm{HCl}(1 \mathrm{wt} \%)$ in dioxanewater solution was recommended, giving satisfactory xylose and glucose yields of $79.7 \%, 91.5 \%$ respectively with a cellulase dosage of 3 FPU $\mathrm{g}^{-1}$ of the substrate.

\subsection{Effect of reaction time and temperature on sugar recovery}

Effect of the time and temperature in the first stage on enzymatic hydrolysis was also evaluated in this research. The experiments were conducted at given temperatures $\left(70{ }^{\circ} \mathrm{C}\right.$, $80{ }^{\circ} \mathrm{C}, 90{ }^{\circ} \mathrm{C}$ ) and times (10 $\mathrm{min}, 20 \mathrm{~min}, 30 \mathrm{~min}, 40 \mathrm{~min}, 50$ $\min )$ in the first stage.

As depicted in Table 3, the sum yield of glucose obtained in the first stage and the second stage was less than $8.0 \%$, which demonstrated that this pretreatment method had little impact on cellulose solubilization due to its tight structure and most of cellulose remained in the pretreated materials. It was worth to notice that the glucose yield in the first stage (acidic dioxane system) was especially low (0.5-1.8\%). A possible reason was that only glycosidic bonds in amorphous region of cellulose in corn stover were cleaved in acidic dioxane system under such mild conditions $\left(70-90{ }^{\circ} \mathrm{C}, 20-50 \mathrm{~min}\right)$. However the glucose 
yield had an increasing trend with the increasing time and prolonging time, which was agreement with the results of $\mathrm{J}$. Zhang. ${ }^{49}$ In his report, they found that the glycosidic bonds could be effectively cleaved in acidic dioxane-water system and $48.3 \%$ D-glucosamine was obtained at $175{ }^{\circ} \mathrm{C}$ for $1 \mathrm{~h}$ during the depolymerization of chitin in acidic dixoane-water system. It was also observed that both reaction temperature and time had positive effects on glucose yield in enzymatic hydrolysis within the time scope of 10-40 min and temperature range of $70-90{ }^{\circ} \mathrm{C}$. The reason was that the accessibility of enzyme to cellulose was improved as much more hemicellulose and lignin were hydrolyzed and removed with increasing temperature and prolonging time. Specifically, a high glucose yield of $91.5 \%$ was obtained with 3 FPU g ${ }^{-1}$ cellulose at $90{ }^{\circ} \mathrm{C}$ for $20 \mathrm{~min}$ but no significant increase was discovered prolonging time from 20-40 min. Also, reaction condition, whereas, it exhibited a decreasing tendency further prolonging time mainly because of the propensity of xylose into furfural or other by-products in acidic environment. ${ }^{\mathbf{4 6 , 4 7}}$ Comprehensively considering glucose and xylose yield as well as energy consumption, $90{ }^{\circ} \mathrm{C}, 20 \mathrm{~min}$ was employed as the appropriate reaction condition for $\mathrm{ADPH}$.

\subsection{Characterization of corn stover pretreated and untreated}

As discussed above, the enhancement of carbohydrates accessibility to enzyme by pretreatment had a strong association with the physical structure or altered chemical composition of biomass. To further understand $\mathrm{ADPH}$ pretreatment, the specific surface area, pore volume and morphology feature of biomass before and after pretreatment were characterized by BET and SEM.

Porosity is an important factor that can influence the efficiency of enzymatic hydrolysis. The specific surface area (SSA) and pore volume of untreated, HP, ADP and ADHP materials were determined, with the results listed in Table 4. As depicted in Table 4, the SSA and pore volume of untreated samples was small, which demonstrated that the structure of raw material was compact and it was difficult to be hydrolyzed by enzyme. However, both SSA and pore volume increased no matter which pretreatment method was adopted because of the hemicelluloses and lignin removal. As shown in Table 4, after HP, SSA increased from 1.5444 to $3.8816 \mathrm{~m}^{2} \mathrm{~g}^{-1}$ while pore volume increased from 0.0022 to $0.0174 \mathrm{~cm}^{3} \mathrm{~g}^{-1}$. This could be

Table 4 Porosity of corn stover untreated and pretreated by different methods

\begin{tabular}{lllll}
\hline & Untreated & $\mathrm{AP}^{a}$ & $\mathrm{ADP}^{b}$ & $\mathrm{ADPH}^{c}$ \\
\hline $\mathrm{SSA}^{d}\left(\mathrm{~m}^{2} \mathrm{~g}^{-1}\right)$ & 1.5444 & 3.8816 & 4.2841 & 5.1265 \\
Pore volumed $\left(\mathrm{cm}^{3}\right.$ & 0.0022 & 0.0174 & 0.0080 & 0.0108
\end{tabular}

$\mathrm{g}^{-1}$ )

${ }^{a}$ Treated only with $1 \mathrm{wt} \% \mathrm{HCl}$ at $120{ }^{\circ} \mathrm{C}$ for $40 \mathrm{~min} .{ }^{b}$ Treated only with 9/1 (v/v) $1 \mathrm{wt} \% \mathrm{HCl}$ dioxane-water solution at $90{ }^{\circ} \mathrm{C}$ for $20 \mathrm{~min} .{ }^{c}$ Treated with $9 / 1(\mathrm{v} / \mathrm{v}) 1 \mathrm{wt} \% \mathrm{HCl}$ dioxane-water solution at $90^{\circ} \mathrm{C}$ for $20 \mathrm{~min}$ and followed by $1 \mathrm{wt} \% \mathrm{HCl}$ at $120{ }^{\circ} \mathrm{C}$ for $40 \mathrm{~min} .{ }^{d} \mathrm{SSA}$ represents specific surface area measured by $\mathrm{N}_{2}$ absorption method. triggered by the removal of hemicelluloses. Compared to HP, ADP process caused SAA increased to $4.281 \mathrm{~m}^{2} \mathrm{~g}^{-1}$ and the pore volume decreased to $0.0080 \mathrm{~cm}^{3} \mathrm{~g}^{-1}$ (Table 4). A possible reason was that the removal of the lignin (43.9\% lignin) during ADP process caused the structural collapse and disruption of corn stover particles. And this collapse and disruption of particles could improve the specific surface area of biomass and reduce the pore volume. In the case of the ADPH process, the impact was prominently strengthened, which led to further increases of total pore volume and specific surface area (SAA $3.8816 \mathrm{~m}^{2} \mathrm{~g}^{-1}$, pore volume $0.0108 \mathrm{~cm}^{3} \mathrm{~g}^{-1}$, Table 4) because plenty of lignin and hemicellulose was removed. This helped to explain the reason why $\mathrm{ADPH}$ enable biomass to achieve a high enzymatic hydrolysis yield.

Fig. 3 showed the SEM images of untreated corn stover, samples after HP, ADP and ADPH process. Fig. 3a illustrated that untreated corn stover exhibited a non-porous, tight and glossy structure, which enabled cellulose to possess a natural shield against enzymatic attack. Fig. 3b showed that the compact structure was partially damaged after HP pretreatment. Comparing with raw material, the fibers became fluff and some pores were founded on the surface of corn fiber, which improved the accessibility between cellulose and enzyme. The possible reason was that dilute hydrochloric acid, as a catalyst, could break the bonds existed in hemicelluloses and LCC, ${ }^{\mathbf{5 0}}$ resulting in most of hemicelluloses degraded into xylose $(83.9 \%$ xylose obtained). From Fig. 3c, it seemed that the surface architecture of corn stover after ADP process was damaged to a larger extent than that of HP process. It was due to the fact that $\mathrm{H}^{+}$in acidic dioxane solution cleaved the same bonds as well as it did in HP process, but caused segmental hemicelluloses and a large amount of lignin dissolved into acidic dioxane solution (49.8\% lignin and 31.5\% xylose obtained). After ADPH, much lignin and hemicelluloses (49.8\% lignin recovery and $72.5 \%$ xylose yield) was removed from the biomass, which severely destroyed the surface of samples, and resulted in a highly rough and irregular morphology (Fig. 3d), causing a significant increase of surface area which had a beneficial influence on the

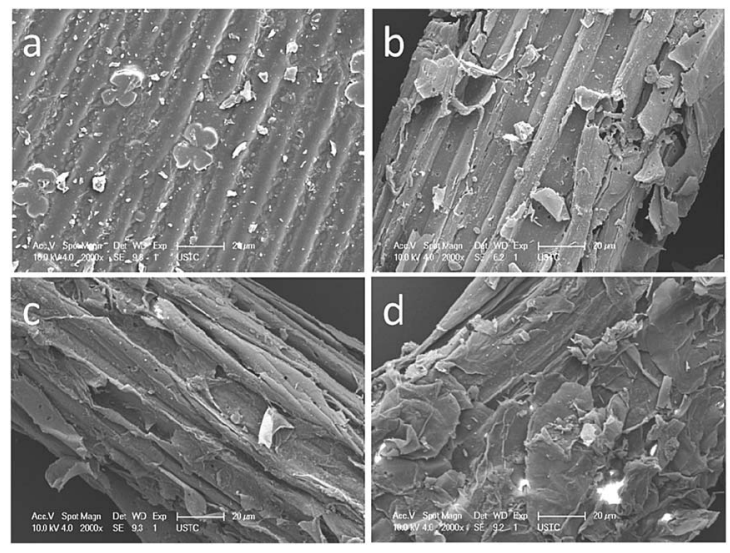

Fig. 3 The surface appearance of (a) untreated, (b) $\mathrm{HCl}$ pretreated, (c) acidic dioxane pretreated and (d) two stage pretreated with acidic dioxane used in the first stage. 
enzymatic hydrolysis. This result suggested that ADPH was an available method to improve enzymatic hydrolysis of cellulose by removing lignin and hemicelluloses.

Degree of polymerization (DP) could represent glucan chain length, which was deemed as one of the factors affecting enzymatic hydrolysis. The DPv changes could reflect the effect of pretreatment on corn stover and it was determined according the method mentioned in 2.4.6. Through determination, the $\mathrm{DPv}$ of untreated, HP-pretreated, ADP-pretreated and ADPH pretreated corn stover was 6498, 2332, 2153, 1446, respectively. After HP, ADP and ADPH pretreatment, the DPv was reduced by $64 \%, 67 \%, 78 \%$ as compared with that of untreated corn stover. Lower DPv value demonstrated shorter glucan chain length, which would improve the glucose yield in enzyme hydrolysis by increasing the specific surface area of material and the binding sites of cellulase.

\section{Conclusions}

The two-stage pretreatment using acidic dioxane followed by dilute hydrochloric acid could efficiently recover glucose from enzymatic hydrolysis. The impact of temperature, time, dioxane-to-water ratio, acid concentration in the first stage were investigated to determine the optimum pretreatment conditions. Under optimal conditions $\left(90{ }^{\circ} \mathrm{C}, 20 \mathrm{~min}, 9 / 1\right.$ (v/v) dioxane-water including $1.0 \mathrm{wt} \% \mathrm{HCl}$ solution in the first stage followed by $120{ }^{\circ} \mathrm{C}$ and $40 \mathrm{~min}$ for $1.0 \mathrm{wt} \%$ dilute hydrochloric acid in the second stage), 91.5\% glucose and $79.7 \%$ xylose (including $7.2 \%$ from enzymatic hydrolysis) could be recovered with an enzyme dosage of $3 \mathrm{FPU} \mathrm{g}^{-1}$ substrate. The two-stage pretreatment showed the importance of both hemicelluloses and lignin removal on overall sugar recovery. After pretreatment, the specific surface area and pore volume increased, which improved the accessibility of enzymes to the cellulose.

\section{Acknowledgements}

This study was financially supported by the State Key Program of National Natural Science Foundation of China (51536009), Science and Technological Fund of Anhui Province for Outstanding Youth (1508085J01), the National Key Technology R\&D Program of China (No. 2015BAD15B06) and the international technology cooperation plan of Anhui (No. 1503062030).

\section{Notes and references}

1 Y. Kuang, Y. Zhang, B. Zhou, C. Li, Y. Cao, L. Li and L. Zeng, Renewable Sustainable Energy Rev., 2016, 59, 504-513.

2 S. M. Shafie, Renewable Sustainable Energy Rev., 2016, 59, 1089-1100.

3 S. Alipour and H. Omidvarborna, RSC Adv., 2016, 6, 111616111621.

4 B. M. Upton and A. M. Kasko, Chem. Rev., 2015, 11, 22752306.

5 J. N. Putro, F. E. Soetaredjo, S. Y. Lin, Y. H. Ju and S. Ismadji, RSC Adv., 2016, 6, 46834-46852.
6 M. E. Himmel, S. Y. Ding, D. K. Johnson, W. S. Adney, M. R. Nimlos, J. W. Brady and T. D. Foust, Science, 2007, 315, 804-807.

7 R. Ravindran and A. K. Jaiswal, Bioresour. Technol., 2016, 199, 92-102.

8 Q. Liu, W. Li, Q. Ma, S. An, M. Li, H. Jameel and H. M. Chang, Bioresour. Technol., 2016, 211, 435-442.

9 S. M. Kim, M. E. Tumbleson, K. D. Rausch and V. Singh, Bioresour. Technol., 2017, 232, 297-303.

10 A. Djioleu and D. J. Carrier, ACS Sustainable Chem. Eng., 2016, 4, 4124-4130.

11 J. Zhang, S. Shao and J. Bao, Bioresour. Technol., 2016, 201, 355-359.

12 G. D. Saratale and M. K. Oh, RSC Adv., 2015, 5, 97171-97179.

13 M. C. Coimbra, A. Duque, F. Saéz, P. Manzanares, C. H. Garcia-Cruz and M. Ballesteros, Renewable Energy, 2016, 86, 1060-1068.

14 M. Michelin and J. A. Teixeira, Bioresour. Technol., 2016, 216, 862-869.

15 X. Zhuang, W. Wang, Q. Yu, W. Qi, Q. Wang, X. Tan and Z. Yuan, Bioresour. Technol., 2016, 199, 68-75.

16 K. Zhang, Z. Pei and D. Wang, Bioresour. Technol., 2016, 199, 21-33.

17 K. Zhang, Z. Pei and D. Wang, Bioresour. Technol., 2016, 2133.

18 X. Sun, X. Sun and F. Zhang, RSC Adv., 2016, 6, 99455-99466.

19 R. Financie, M. Moniruzzaman and Y. Uemura, J. Chem. Eng., 2016, 110, 1-7.

20 R. Sindhu, P. Binod and A. Pandey, Bioresour. Technol., 2016, 199, 76-82.

21 M. García-Torreiro, M. López-Abelairas, T. A. Lu-Chau and M. Lema, Ind. Crops Prod., 2016, 89, 486-492.

22 V. Chang and M. Holtzapple, Appl. Biochem. Biotechnol., 2000, 84-86, 5-37.

23 P. Phitsuwan, K. Sakka and K. Ratanakhanokchai, Biomass Bioenergy, 2013, 58, 390-405.

24 R. Ravindran and A. K. Jaiswal, Bioresour. Technol., 2016, 199, 92-102.

25 S. M. Kim, B. S. Dien, M. E. Tumbleson, K. D. Rausch and V. Singh, Bioresour. Technol., 2016, 216, 706-713.

26 G. Brodeur, J. Telotte, J. J. Stickel and S. Ramakrishnan, Bioresour. Technol., 2016, 220, 621-628.

27 L. Mesa, E. González, C. Cara, M. González, E. Castro and S. I. Mussatto, J. Chem. Eng., 2011, 168, 1157-1162.

28 W. Li, Q. Liu, Q. Ma, T. Zhang, L. Ma, H. Jameel and H. M. Chang, Bioresour. Technol., 2016, 219, 753-756.

29 F. A. Perras, H. Luo, X. Zhang, N. S. Mosier, M. Pruski and M. M. Abu-Omar, J. Phys. Chem. A, 2016, 121, 623-630.

30 A. Berlin, M. Balakshin, N. Gilkes, J. Kadla, V. Maximenko, S. Kubo and J. Saddler, J. Biotechnol., 2006, 125, 198-209.

31 J. K. Saini, A. K. Patel, M. Adsul and R. R. Singhania, Renewable Energy, 2016, 98, 29-42.

32 B. B. Hewetson, X. Zhang and N. S. Mosier, Energy Fuels, 2016, 30, 9975-9977.

33 G. Guo, S. Li, L. Wang, S. Ren and G. Fang, Bioresour. Technol., 2013, 135, 738-741. 
34 Q. Qing, B. Yang and C. E. Wyman, Bioresour. Technol., 2010, 101, 9624-9630.

35 X. Wang, K. Li, M. Yang and J. Zhang, Carbohydr. Polym., 2016, 148, 362-370.

36 S. Zu, W. Z. Li, M. Zhang, Z. Li, Z. Wang, H. Jameel and H. M. Chang, Bioresour. Technol., 2014, 152, 364-370.

37 T. Ghose, Pure Appl. Chem., 1987, 59, 257-268.

38 A. Sluiter, B. Hames, R. Ruiz, C. Scarlata, J. Sluiter, D. Templeton and D. Crocker, Determination of structuralcarbohydrates and lignin in biomass, NREL, 2008.

39 A. Sluiter, R. Ruiz, C. Scarlata, J. Sluiter and D. Templeton, Determination of Extractives in Biomass, Laboratory Analytical Procedure (LAP), NREL, 2005.

40 A. Sluiter, B. Hames, D. Hyman, C. Payne, R. Ruiz, C. Scarlata, J. Sluiter, D. Templeton and J. Wolfe, Determination of Total Solids in Biomass and Total Dissolved Solids in Liquid Process Samples, NREL, 2008.

41 W. J. Huijgen, J. H. Reith and H. D. Uil, Ind. Eng. Chem. Res., 2010, 49, 10132-10140.
42 ASTM, Standard test method for intrinsic viscosity of cellulose (D 1795), Am. Soc. Test. Master, 1986, vol. 15, pp. 360-366.

43 R. Kumar, G. Mago, V. Balan and C. E. Wyman, Bioresour. Technol., 2009, 100, 3948-3962.

44 H. Y. Li, X. Chen and C. Z. Wang, Biotechnol. Biofuels, 2016, 9, 166-179.

45 T. Renders, W. Schutyser, S. V. Bosch and S. F. Koelewijn, ACS Catal., 2016, 6, 2055-2066.

46 D. E. Kim and X. Pan, Ind. Eng. Chem. Res., 2010, 49, 1215612163.

47 W. J. Huijgen, A. T. Smit, J. H. Reith and H. D. Uil, J. Chem. Technol. Biotechnol., 2011, 86, 1428-1438.

48 Y. L. Loow, T. Y. Wu, J. M. Jahim, A. W. Mohammad and W. H. Teoh, Cellulose, 2016, 23, 1491-1520.

49 J. Zhang and N. Yan, ChemcatChem, 2017, DOI: 10.1002/ cctc. 201601715.

50 X. Ye, Z. Zhang, Y. Chen, J. Cheng, Z. Tang and Y. Hu, Ind. Crops Prod., 2016, 87, 280-286. 